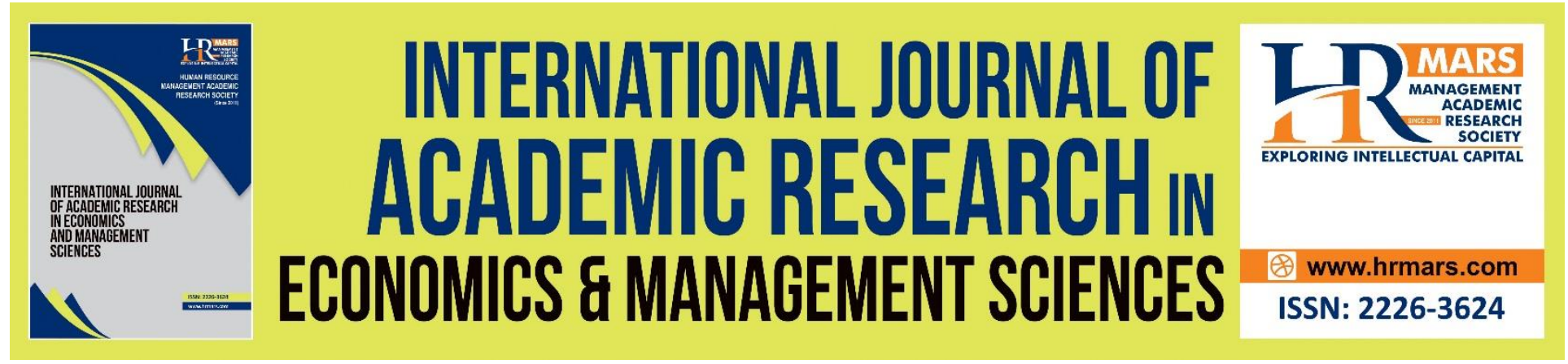

\title{
The Relationship between Macroeconomic Factors and Tourism Demand for ASEAN Countries
}

\author{
Saizal Bin Pinjaman, Marry Tracy Pawan
}

To Link this Article: http://dx.doi.org/10.6007/IJAREMS/v10-i3/11051

DOI:10.6007/IJAREMS/v10-i3/11051

Received: 08 June 2021, Revised: 30 June 2021, Accepted: 06 July 2021

Published Online: 24 September 2021

In-Text Citation: (Pinjaman \& Pawan, 2021)

To Cite this Article: Pinjaman, S. Bin, \& Pawan, M. T. (2021). The Relationship between Macroeconomic Factors and Tourism Demand for ASEAN Countries. International Journal of Academic Research in Economics and Managment and Sciences, 10(3), 212-222.

Copyright: (C) 2021 The Author(s)

Published by Human Resource Management Academic Research Society (www.hrmars.com)

This article is published under the Creative Commons Attribution (CC BY 4.0) license. Anyone may reproduce, distribute, translate and create derivative works of this article (for both commercial and non-commercial purposes), subject to full attribution to the original publication and authors. The full terms of this license may be seen

at: http://creativecommons.org/licences/by/4.0/legalcode

Vol. 10, No. 3, 2021, Pg. 212 - 222

http://hrmars.com/index.php/pages/detail/IJAREMS

JOURNAL HOMEPAGE

Full Terms \& Conditions of access and use can be found at http://hrmars.com/index.php/pages/detail/publication-ethics 


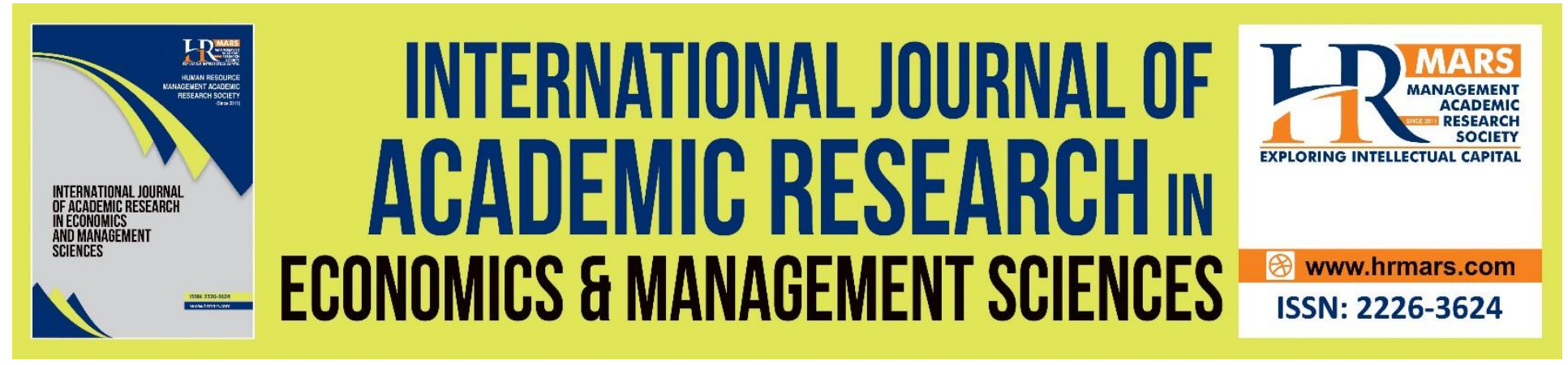

\title{
The Relationship between Macroeconomic Factors and Tourism Demand for ASEAN Countries
}

\author{
Saizal Bin Pinjaman, Marry Tracy Pawan \\ Faculty of Business, Economics and Accountancy, Universiti Malaysia Sabah \\ Email: saizal@ums.edu.my
}

\begin{abstract}
The current paper investigates the relationship between macroeconomic factors and tourism demand for nine selected ASEAN countries. Based on the panel data analysis, it is identified that income is positively related to tourism demand where an increase in the level of income for ASEAN leads to higher tourist arrival to the region. The income is also shown to be the most important factor that determines tourism demand as demonstrated by the high coefficient value in the estimation. The appreciation of ASEAN currencies meanwhile is identified to discourage tourists from visiting the region and on the other hand, trade openness stimulates the demand as it implies the ease of entry. Since majority of the tourist came from developed countries with high purchasing power, price level is identified to be not significant in explaining the movement of tourism demand in the region. To develop the tourism sector, proper plans should be made including to improve the infrastructure, tourism facility and travel safety, and ease of entry considering the positive impact of economic development and trade openness. Relevant strategies should also be made to attract tourists from countries with higher purchasing power and strong currency value since it implies to be important in explaining the movement of tourism demand.
\end{abstract}

Keywords: Tourism Demand, Macroeconomic Factors, ASEAN Countries

\section{Introduction}

ASEAN is a major tourist destination and majority of the tourists came from North America, European countries, and China. Based on Figure 1 below, over 1 billion visitors have traveled to the region for the last 11 years. The number rose from just 66 million in 2008 to almost 135 million in 2019, an increase of 108 percent. Among the 11 ASEAN countries, Thailand, Malaysia, Singapore, Vietnam, and Indonesia handle more than half of the arrival. 


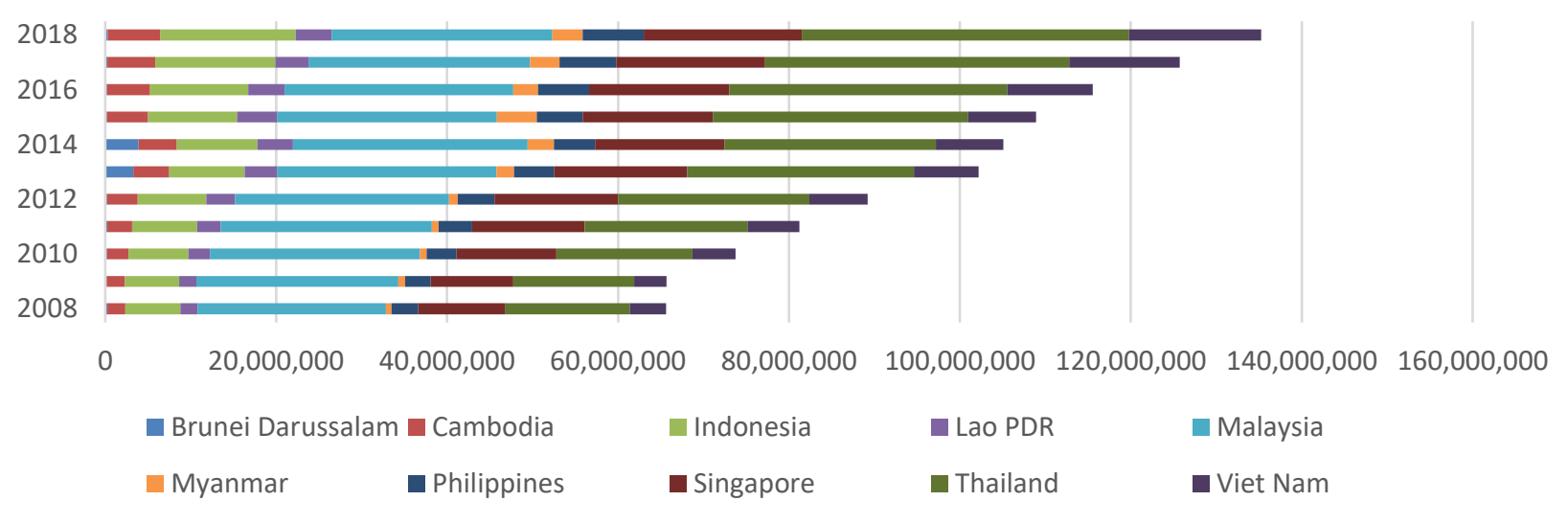

Figure 1: Visitors Arrival to ASEAN (in Volume)

Source: AseanStats (2018)

By rank, Thailand hosts the largest number of visitors with over 38 million in 2018 and this is followed by Malaysia and Singapore with over 25 million and 18 million visitors, respectively. Indonesia and Vietnam meanwhile handle over 15 million visitors each in that same year. Nevertheless, a significantly high number of visitors is also demonstrated by the other ASEAN members.

The growing importance and the dependence of the region on the tourism sector can be seen based on the increase of export for travel service as shown in Figure 2. In 2010, the export value for travel is USD 68 billion and rose 51 percent to USD 139 billion in just 8 years. Travel is the largest export in services for ASEAN since 2013 and covers 34 percent of the total export in services. For comparison, the total volume of export for Financial and Transport services in 2018 are just USD 30 billion and USD 75 billion, respectively. With the increasing number of tourists that visit the region, comes a number of economic and social benefits such as generating output and household income (Abdullah, 2012; Ren et al., 2019), change in moral values (Zhuang, et al., 2019), and bridging the people from different backgrounds, cultures, and traditions (Paul, 2012).

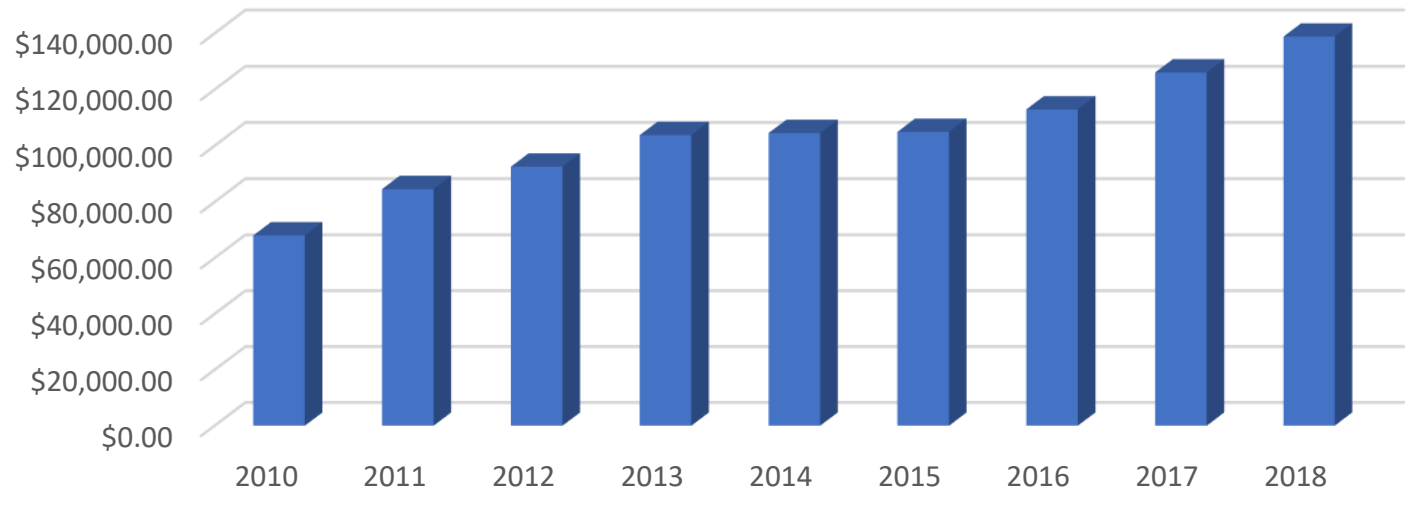

Figure 2: Export in Travel Services for ASEAN countries (in Million USD) Source: AseanStats (2018) 
Although the number of visitors' arrival to ASEAN increased steadily, the percentage of change in the arrival is precarious as demonstrated in Figure 3. In 1998, the percentage of change in arrival was -5 percent before it moves to 15 percent in 1999. Five years later in 2003, ASEAN saw the hardest hit in the percentage of change in arrival with -12 percent and then increase by 40 percent to reach the highest rate the year after. The percentage of change in arrival to ASEAN continues to move in uncertain trends for the following years where in 2018, the rate was just 7.6 percent and it is 7.4 percent lower than the rate 10 years back.

This brings an important question, what factors determine the tourist arrival or tourism demand in the region? Researches such as Hanafiah et al (2010); Soofi et al (2018) claim that macroeconomic factors such as income, exchange rate, and trade openness are significant in influencing tourism demand. However, these analyses have been conducted not in the case of ASEAN. The number of literatures that focus on the region is rather limited. Apart from that, the findings based on previous researches are somewhat ambiguous. Borhan and Arsad (2018) for example believe that income and trade openness was not found to exert as important determinants on tourism demand. But this is contradicted with Hanafiah et al (2010) and Rasekhi and Mohammadi (2017) who suggested otherwise. The heterogeneity in the relationship between macroeconomic variables and tourism demand causes the findings to be different across markets.

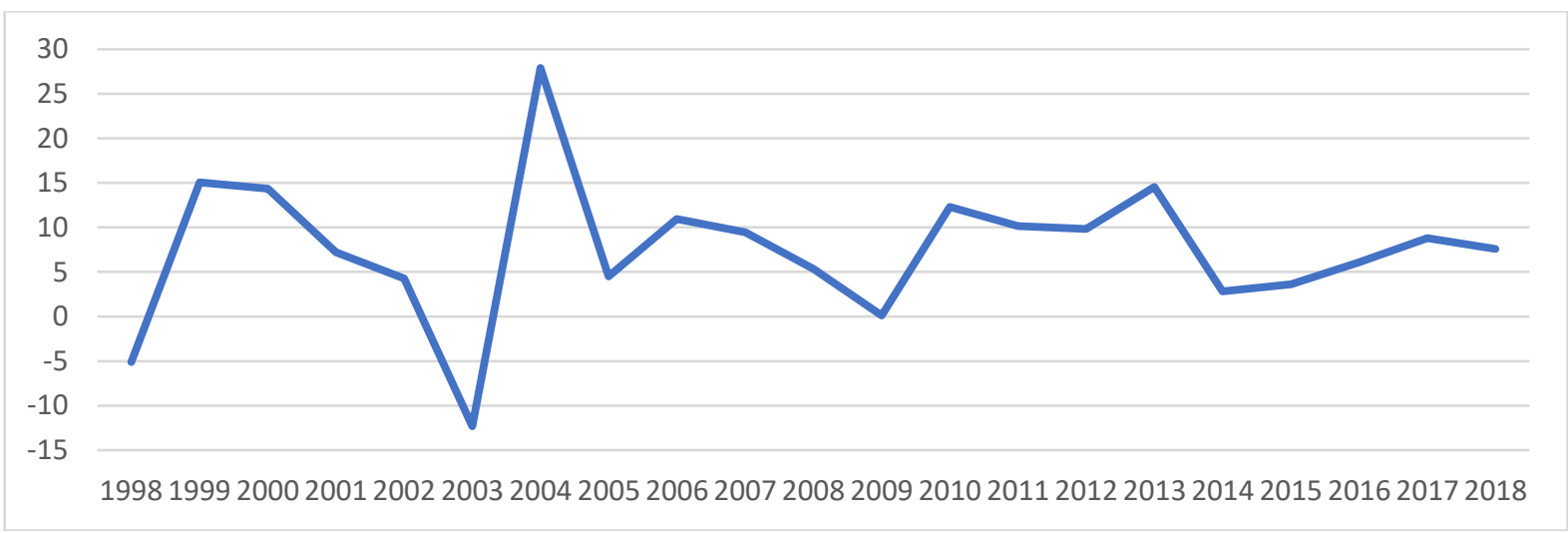

Figure 3: Visitors arrival from the rest of the world to ASEAN (Percentage of change) Source: AseanStats (2018)

The scarce literatures that have been conducted in the region and the ambiguity of the relationship between macroeconomic factors and tourism demand lead to a potential risk to the tourism sector. This is because the precarious movement of tourism demand in the region may be influenced by macroeconomic factors. But the absence of this vital information causes policymakers to construct strategies that may not just ineffective but harms the tourism industry as well. By considering the role of ASEAN as one of the world's major tourist destinations and its heavy dependence on the sector, an analysis should be conducted to identify the relationship between these macroeconomic factors and tourism demand. This will help the policymakers to understand the relationship between the variables in the case of ASEAN and create a relevant 
approach to tackle the issue of precarious tourism demand. Apart from that, the current paper can also be used as a reference or extended for future analyses.

The remainder of the current paper is organized as follows: Section 2 discusses previous literature on tourism demand and macroeconomic determinants. Section 3 meanwhile describes the data as well as panel data analysis. Section 4 analyses the relationship between macroeconomic factors and tourism demand, while Section 5 summarizes the main results as well as providing the implications of the research.

\section{Literature Review}

Song and Witt (2000) described tourism demand as the amount of a set of tourist products that the consumers are willing to acquire during a specific period and under certain conditions which are controlled by the explanatory factors used in the demand equation. Analyzing the impact of macroeconomic factors on tourism demand, Song et al (2016) proxy tourism demand by tourist arrivals and tourist expenditures with Hong Kong has been chosen as the destination country while Australia, the USA, and the UK are chosen as origin countries. Based on the data that covers the period from 1981 to 2006, Song et al (2016) argue that tourism demand that is proxied by tourist arrivals is more influenced by income while tourism demand based on tourism expenditures is more likely to be determined by the real exchange rate.

Focusing on the impact of macroeconomic factors on tourism demand in Malaysia, Hanafiah et al (2011) employed a regression analysis on a model that contains the gross domestic product of the origin countries, relative price, and trade. Hanafiah et al (2011) believe that the selected macroeconomic factors are identified to be important in explaining the movement of tourism demand in the country where the increase in the income per capita in the country of origin and trade openness will lead to higher tourism demand. Meanwhile, Hanafiah et al (2011) identify that the upward trend in relative price discourages tourism demand as it represents the increase in the cost of tourism.

Analyzing the impact of income and exchange rate on tourism demand, Untong et al (2015) conducted a study in Thailand between 1998 and 2013 the arrival of tourists from China is used as the independent variable while the gross domestic product of China and real exchange rate of Thailand and its competitors act as the independent variables. According to Untong et al (2015), Thailand is considered to be a luxury market for Chinese tourists and the tourism demand is elastic towards the economic development of China. Additionally, tourists from China are identified to respond less to price changes from Thailand than from the other competitors. Untong et al (2015) also provide evidence that the exchange rate is negatively correlated with international tourism arrivals. This is similar to Khandaker and Islam (2017) who found that the exchange rate plays an important factor in the tourism sector where a lower exchange rate is more desirable for the growth of a tourism-based economy.

Meanwhile, Wakimin et al (2018) conducted a study aimed to determine the main factors that could affect tourism demand in ASEAN-5 countries, namely Malaysia, Indonesia, Singapore, Thailand, and the Philippines. Panel Data analysis, with Pooled Mean Group (PMG), Mean Group 
(MG), and Dynamic Fixed Effect (DFE) are applied and Wakimin et al (2018) said that the results are consistent with the theory of demand. Wakimin et al (2018) argue that income per capita and trade appeared to exert significant positive relationship with tourism demand where an increase in income per capita and trade leads to a higher level of tourism demand. On the other hand, tourism price has a negative relationship with tourism demand in the region. It implies that an increase in tourism price, represented by the total value of consumer price index and the exchange rate, causes tourism demand to be lower.

Focusing on the impact of trade openness on the tourism sector, Chaisumpunsakul and Pholphirul (2018) conducted a study to analyse the relationship between international trade and international tourism demand in Thailand. The study shows that the degree of trade openness is positively related to international tourism demand. This result is consistent with the research of Habibi et al (2009) who analyze the international tourism demand in Malaysia where it is discovered that the 1 percent increase in international trade causes an increase in the number of international tourist arrivals to Malaysia by 0.02 percent in the long term.

Soofi et al (2018), on the other hand, conducted a study on the macroeconomic factors that affect tourism demands for the Organization of Islamic Countries (OIC). Instead of using the gross domestic product of the country of origin as Hanafiah et al. (2011) and Untong et al. (2016), Ali Soofi et al. (2018) meanwhile study the impact of gross domestic product of the host countries. By using the generalized least square (GLS) method, Ali Soofi et al. (2018) believe that GDP per capita of the host countries, together with the real exchange rate, population, trade openness has positive relationship with tourist arrival where an increase in the level of these macroeconomic factors will lead to similar movement on the tourism demand. The results also show that although the Consumer price index (CPI) variable has a positive sign on its coefficient, the CPI is identified to be insignificant in explaining tourism demand. Ali Soofi et al. (2018) argue that implementing the appropriate exchange rate in line with tourism development, policies and economic adoption can help to reduce travel costs and enhances the competitive advantage of this industry.

\section{Data and Methodology}

The current paper collected the data for nine selected ASEAN countries, namely Brunei, Cambodia, Indonesia, Malaysia, Singapore, Thailand, The Philippines, and Vietnam that span for 23 years based on the data from the Worldbank Databank and ASEANstats. The reason why this study focuses on the nine countries and excluded Myanmar and Timor Leste that are also members of ASEAN is due to the unavailability of data. By referring to previous studies, the current paper uses four macroeconomic factors that act as independent variables, namely i) Gross Domestic Product of ASEAN countries, ii) Exchange rate, iii) Consumer Price Index, and iv) Trade openness. The number of visitors' arrival meanwhile acts as a proxy for tourism demand in the current study. All variables are transformed into natural logarithm where the coefficients on the natural logarithm scale are directly interpretable as approximate proportional differences (Gelman \& Hill, 2006). 
The gross domestic product per capita for the host country is used as a proxy for income per capita while the exchange rate is represented based on the nominal value of the ASEAN currencies against the US dollar ${ }^{1}$. The increase in the value of the exchange rate implies the depreciation of the local currencies against US dollar. Relating to price, consumer price index in the ASEAN countries is considered as the proxy for the cost of tourism where an increase in the consumer price index represents higher cost of tourism. In order to construct the trade openness of ASEAN, the current paper utilizes the formula shown below:

Trade Openness $=\frac{\text { Export }_{A}+\text { Import }_{A}}{\boldsymbol{G D P}_{A}}$

Where:

Export $_{\mathrm{A}}=$ Export of ASEAN countries

Import $\mathrm{C}=$ Import of ASEAN countries

$\mathrm{GDP}_{\mathrm{A}}=$ Gross Domestic Product of ASEAN

\section{The Random Effects Model}

According to Hill et al. (2008), random effects model assumes that all individual differences are captured by the intercept parameters just like fixed effects model. But the difference is that in random effects model, the individual differences are treated as random rather than fixed.

The random effects model can be written as:

$y_{i t}=\beta_{0}+x^{\prime}{ }_{i t} \beta+\left(\alpha_{i}+u_{i t}\right), i=1, \ldots, N$ (individual firms), $t=1, \ldots, T$ (Time)

$u_{i t} \sim I I D\left(0, \sigma_{u}^{2}\right) ; \alpha_{i} \sim I I D\left(0, \sigma_{\alpha}^{2}\right)$

The first error component or $\alpha_{i}$ is an individual specific component of the error term that fixed over time and attributed to all the error terms correlations ${ }^{2}$. The second error component or $u_{i t}$, on the other hand, is assumed to be uncorrelated and vary over time ${ }^{3}$. The estimation of $\beta_{0}$ and $\beta$ can be done using Generalized Least Square (GLS) estimator by transforming OLS estimators to obtain an equation that contains quasi-demeaned data:

$\left(y_{i t}-\vartheta \bar{y}_{i}\right)=\beta_{0}(1-\vartheta)+\left(x_{i t}-\vartheta \bar{x}_{i}\right)^{\prime} \beta+\left(v_{i t}-\vartheta \bar{v}_{i}\right)$,

Where:

$\vartheta=1-\psi^{1 / 2}$ and that $\psi=\frac{\sigma_{u}^{2}}{\sigma_{u}^{2}+T \sigma_{\alpha}^{2}}$.

1 Exchange rate is used instead of the real effective exchange rate due to data limitation. This is similar to the method used by researchers such as Gan (2015) and Borhan and Arsad (2018).

${ }^{2}$ According to Verbeek (2012), $\alpha_{i}$ and $u_{i t}$ are assumed to be mutually independent and independent of $x_{j s}$ (for all firm, $j$ and time, $s$ ) and that estimating $\beta_{0}$ and $\beta$ by using OLS estimator is consistent and unbiased.

${ }^{3}$ Unless $\sigma_{\alpha}^{2}=0$, the error terms $\alpha_{i}+u_{i t}$ are autocorrelated and the estimated standard errors of the regressors based on OLS estimators will be incorrect. 
The composite error term $v_{i t}=\left(\alpha_{i}+u_{i t}\right)$ is serially correlated across time as $\alpha_{i}$ is present in each time period. But transforming the model into Equation (3) eliminates the serial correlation and leads to the error term $\left(v_{i t}-\vartheta \bar{v}_{i}\right)$ that is now IID over individuals and time. In order to estimate the unknown variance components $\sigma_{\alpha}^{2}$ and $\sigma_{u}^{2}$ in Equation (3), Feasible GLS estimator or EGLS can be used where $\hat{\sigma}_{u}^{2}=\frac{1}{N(T-1)} \sum_{i=1}^{N} \sum_{t=1}^{T} \hat{u}_{i t}^{2}$ meanwhile $\hat{\sigma}_{\alpha}^{2}=\hat{\sigma}_{B}^{2}-\frac{1}{T} \hat{\sigma}_{u}^{2}$, respectively 4 .

\section{Result Analysis}

Based on the Hausman test, Random Effects model is preferred over Fixed Effects model since the unique error terms $\left(\alpha_{i}\right)$ are identified to be not correlated with the regressors. Breush-Pagan Lagrangian test, on the other hand, indicates significant differences across countries and suggests the suitability of the Random Effects model over the simple Pooled OLS. By referring to these two arguments, the current paper focuses on the results of Random Effects model. Regarding the robustness and the efficiency of the Random Effects model, it is identified that the overall RSquared indicates that 70 percent of the observations are explained by the model. The Wald test meanwhile shows that all coefficients in the model are significantly different than zero.

Table 1: The Results of Random Effects Estimation on the Macroeconomic Factors and Tourism Demand for Selected ASEAN Countries

\begin{tabular}{|l|c|}
\hline Variables & Random Effects Model \\
\hline Income per Capita & $1.788714^{* * *}$ \\
& $(0.1773)$ \\
\hline Exchange Rate & $0.2495^{* *}$ \\
& $(0.1032)$ \\
\hline Trade Openness & $0.4519678^{* *}$ \\
& $(0.1872)$ \\
\hline Consumer Price Index & -0.0773 \\
& $(0.0762)$ \\
\hline Constant & -0.5931 \\
& $(1.6138)$ \\
\hline R-Square & 0.6987 \\
\hline Wald Chi-Square & 423.94 \\
\hline Probability (Chi-Square) & 0.0000 \\
\hline Observation & 207 \\
\hline
\end{tabular}

Note: Dependent variable is the tourism demand from the world towards nine individual ASEAN countries. All variables are expressed in natural logarithm. Standard errors for dependent variables are shown in parentheses with $*, * *, * *$ indicate statistical significance at $10 \%, 5 \%$ and $1 \%$ level, respectively.

${ }^{4}$ Where $\hat{\sigma}_{B}^{2}=\frac{1}{N} \sum_{i=1}^{N}\left(\bar{y}_{i}-\hat{\beta}_{0 B}-\bar{x}_{i}^{\prime} \hat{\beta}_{B}\right)^{2}$ and $\hat{\beta}_{0 B}$ is the between estimator for $\beta_{0}$. The estimator $\beta_{0}$ and $\beta$ obtained from Feasible GLS is referred to as the Random Effects estimator. 
By referring to Table 1, three variables are identified to be significant with positive relationship with tourism demand in ASEAN countries. These variables are the income per capita, exchange rate, and trade openness. The consumer price index meanwhile exhibits a negative sign on the coefficient, but the relationship is found to be insignificant. Based on the high value of its coefficient, income per capita is demonstrated to be the most dominant factor that explains tourism demand. At 1 percent significance level, a 1 percent increase in income causes the tourism demand to move in a similar direction by 1.79 percent. This shows that tourism demand is elastic towards income. Meanwhile, it is found that a 1 percent increase in the exchange rate and trade openness contribute to an increase in tourism demand by 0.25 percent and 0.45 percent, respectively. Although significant at 5 percent level, tourism demand is demonstrated to be inelastic towards exchange rate and trade openness as shown by the coefficient values that are lower than 1.

The negative sign in the coefficient value for the consumer price index signals the inverse correlation between the variables and based on the coefficient value that is lower than one, tourism demand is also inelastic towards price. However, the consumer price index is found to be insignificant in explaining the tourism demand on ASEAN at any level of significance.

\section{Conclusion and Recommendation}

Based on the results, it is identified that income is the most important factor that determines tourism demand for ASEAN countries. Similar to the findings of Hanafiah et al (2011); Gan (2015); Soofi et al (2018), income is identified to be positively related to the tourism demand. It implies that the increase in income per capita for ASEAN causes the tourism demand to go higher. According to Soofi et al (2018), the positive relationship is expected since income per capita is known as an indicator of the level of economic development that could promote tourism receipts. The current paper believes that the increase in the level of economic development implies the improvement in terms of infrastructure, facility, and security that attracts tourists to come to the host countries. This positive relationship is shared by the exchange rate and it is similar to the findings of Yang et al. (2010) and Ali Soofi et al. (2018). The increase in the level of exchange rate suggests the depreciation of the ASEAN currencies against US Dollar. As the ASEAN currencies are relatively cheaper, the tourism demand from the rest of the world will be higher as it is relatively less expensive for tourists to come to ASEAN.

The positive and significant impact of trade openness meanwhile is consistent with Hanafiah et al (2011); Rasekhi and Mohammadi (2017). The current paper argues that an increase in trade openness implies the easiness to travel and encourages tourists to come. However, price was not found to exert an important influence on tourism demand and this coincides with the argument made by Proença and Soukiazis (2005). The increase in price is not large enough to affect the tourist expenditures that mainly come from developed countries with relatively higher purchasing power such as the US, European countries, and China. This also suggests that the policy of low prices may not be effective in motivating tourists to come to ASEAN.

The theory and contextual findings enhance our understanding of the impact of macroeconomic factors on tourism demand in the region. First, the insignificant impact of price suggests an exemption to the law of demand in general where price and demand are deemed to 
exhibit a negative relationship. This is due to the fact that majority of the tourists are from countries with higher purchasing power and that the demand in the context of ASEAN is seen as a luxury product. In addition, the positive and significant influence of income postulates the importance of factors that are associated with growth or economic development such as the improvement in the infrastructure, tourism facilities, and travel safety. It is a major contribution of the study as it looks into the income of ASEAN rather than the country of origin of the tourists. Furthermore, the use of panel data through random effects model allows this study to better understand and measure the effects of macroeconomic variables. It separates the study from the previous attempts that are made mainly on individual countries in ASEAN and based on pure time series analysis.

In summary, the current paper has met its objective and the findings show that the macroeconomic factors are important determinants for the tourism demand in ASEAN countries. The movement of these macroeconomic factors needs to be taken into account by policymakers in planning to strengthen the tourism sectors in the region. To extend the study, some other important variables including social, security, and political factors can be included apart from expanding the sample and utilizing other methods of analysis to thoroughly understand factors that influence tourism demand in the region.

\section{Reference}

Abdullah, R. (2012). The economic impact of tourism in Malaysia: An input output analysis (Doctoral dissertation, Universiti Utara Malaysia).

Ali Soofi, A., Rafsanjani, S., \& Zamanian, G. (2018). Factors affecting tourism demands in selected OIC countries. Environmental Energy and Economic Research, 2(4), 229-236.

Chaisumpunsakul, W., \& Pholphirul, P. (2018). Does international trade promote international tourism demand? Evidence from Thailand's trading partners. Kasetsart Journal of Social Sciences, 39(3), 393-400.

Gelman, A., \& Hill, J. (2006). Data analysis using regression and multilevel/hierarchical models. Cambridge university press.

Gan, Y. (2015). An empirical analysis of the influence of exchange rate and prices on tourism demand (Doctoral dissertation).

Habibi, F., Rahim, K. A., Ramchandran, S., \& Chin, L. (2009). Dynamic model for international tourism demand for Malaysia: Panel data evidence. International Research Journal of Finance and Economics, 33(1), 208-217.

Hanafiah, M. H., Harun, M. F., \& Jamaluddin, M. R. (2011). Trade and tourism demand: A case of Malaysia. In International Conference on Business and Eonomic Research. Malaysia.

Hill, R. C., Griffiths, W. E., \& Lim, G. C. (2008). Principles of Econometrics (3rd ed.). John Wiley \& Sons.

Khandaker, S., \& Islam, S. Z. (2017). International tourism demand and macroeconomic factors. International Journal of Economics and Financial Issues, 7(5), 389-393.

Paul, B. D. (2012). The impacts of tourism on society. Annals of Faculty of Economics, 1(1), 500506. Proença, S. A., \& Soukiazis, E. (2005). Demand for tourism in Portugal: A panel data approach (No. 29). Discussion paper. 
Rasekhi, S., \& Mohammadi, S. (2017). Factors Affecting Tourism Demand in the Caspian Sea Littoral States. Tourism Management Studies, 12(38), 63-81. doi: 10.22054/tms.2017.6434.1148.

Ren, T., Can, M., Paramati, S. R., Fang, J., \& Wu, W. (2019). The Impact of Tourism Quality on Economic Development and Environment: Evidence from Mediterranean Countries. Sustainability, 11(8), 2296. doi:10.3390/su11082296

Song, H. \& Witt, S. F. (2000). Tourism Demand Modelling and Forecasting (1st ed.). Routledge.

Song, H., Li, G., Witt, S. F., \& Fei, B. (2010). Tourism demand modelling and forecasting: how should demand be measured?. Tourism economics, 16(1), 63-81.

Untong, A., Ramos, V., Kaosa-Ard, M., \& Rey-Maquieira, J. (2015). Tourism demand analysis of Chinese arrivals in Thailand. Tourism Economics, 21(6), 1221-1234.

Verbeek, M. (2012). A guide to modern econometrics (4th ed.). John Wiley \& Sons.

Wakimin, N., Azlina, A., \& Hazman, S. (2018). Tourism demand in Asean-5 countries: Evidence from panel data analysis. Management Science Letters, 8(6): 677-690.

Yang, C. H., Lin, H. L., \& Han, C. C. (2010). Analysis of international tourist arrivals in China: The role of World Heritage Sites. Tourism Management, 31(6), 827-837.

Zhuang, X., Yao, Y., \& Li, J. J. (2019). Sociocultural impacts of tourism on residents of world cultural heritage sites in China. Sustainability, 11(3), 840. doi:10.3390/su11030840. 